\title{
Medicines use in hospitalised children: current status and outcome after an intervention
}

\author{
S N Thiyahiny ${ }^{1}$, M G Sathiadas ${ }^{1}$, K Sanchayan ${ }^{1}$, C Vamadevan ${ }^{2}$, R Balasubramaniam ${ }^{3}$, S Sri Ranganathan ${ }^{4}$ \\ (Index words: rational use of medicine, children, Sri Lanka)
}

\begin{abstract}
Introduction Challenges in rational use of medicines (RUM) in children are different from that of adults. In Sri Lanka, data on RUM in children are limited.

Objective To assess the current status and to investigate effectiveness of an intervention in improving RUM in children.
\end{abstract}

Methods Non-randomised controlled before and after study design was employed. Study settings were one paediatric unit in two Teaching Hospitals one for intervention (IU) and the other as a control (CU) unit. After assessing the current status in both units, a combined intervention (one-time training and distribution of a paediatric formulary) was offered to IU and medicine use was re-assessed in both units three months and one year after intervention. Fourteen indicators (7 WHO and 7 developed by investigators) were employed in the assessment. Any improvement was analysed using percentage changes, Chi-square or t tests as appropriate.

Results A total of 1134 charts, 735 (3197 medicines) in IU and 399 (1539 medicines) in CU were subjected to analysis. At base level, of the 14 indicators, 9 were assessed satisfactory in both units. Four could not be assessed without knowing the clinical setting. The remaining indicator, reason for prescribing was recorded for $48 \%$ and $76 \%$ of medicines respectively in IU and $\mathrm{CU}$. After intervention, only three indicators, medicines that had the reason for prescription recorded in the patient records, children treated without regular medicines, and children received the recommended doses of paracetamol, showed favourable changes in three months and one year. Percentage of medicines written in abbreviation showed an undesirable increase in IU $(6.9,16.2,29.6)$ which was higher than what was observed in $\mathrm{CU}(3.2,13.5,18.4)$.

Conclusions Passive interventions appear to be ineffective in improving RUM in children. In addition, general medicine use indicators seem to be insensitive to capture the true challenges in paediatric pharmacotherapy.

Ceylon Medical Journal 2016; 61: 123-129

DOI: http://doi.org/10.4038/cmj.v61i3.8348

\section{Introduction}

Rational use of medicines (RUM) is 'patients receiving medications appropriate to their needs, in doses that meet their own individual requirements, for an adequate period of time, and at the lowest cost to them and their community' [1]. The RUM minimises risk, maximises benefits, saves money, avoids wastage of resources and promotes equity [2]. The World Health Organisation (WHO) acknowledges RUM as a vital strategy in ensuring right medicine in right formulation to every child [3]. Providing good access to efficacious, safe and high quality medicines will not improve child health outcomes unless those medicines are used rationally. Since children are not just small adults, RUM in children has many unique challenges [3-5]. Developed countries have already launched a variety of initiatives to meet these challenges [6].

With the technical support of the WHO, many developing countries have now turned their attention towards RUM in children. The WHO has proposed 12 core interventions to improve RUM, which are general in nature and applicable to all ages [7]. The first step in either promoting a concept or planning an intervention is assessment of the current status. First component of this study was to determine the current status of medicines use in children in two Teaching Hospitals in Sri Lanka.

Of the 12 core interventions proposed by the WHO,

${ }^{1}$ Faculty of Medicine, University of Jaffna, ${ }^{2}$ Teaching Hospital of Batticaloa, ${ }^{3}$ Medical Research Institute, Ministry of Health and ${ }^{4}$ Faculty of Medicine, University of Colombo, Sri Lanka.

Correspondence: SNT, e-mail: <thiyahiny_sunil@hotmail.com>. Received 14 March and revised version accepted 31 May 2016. 
four of them focus on providing training, independent information and education to healthcare professionals. In Sri Lanka, Paediatric Clinical Pharmacology (PCP) is still very much in its infancy despite its steady growth in many other countries. Opportunities, exposure, resources and expertise in PCP are minimal. Training opportunities and independent information sources are also limited for undergraduates, postgraduates, prescribers and other healthcare professionals caring for children. The second component of this study was to investigate effectiveness of an intervention programme, comprising a training workshop and free access to independent information on medicines use in children.

\section{Methods}

It is a non-randomised controlled before and after study design in which observations were made before and after the implementation of an intervention, both in a group that received the intervention and in a control group that did not [8].University Paediatric Unit of Teaching Hospital, Jaffna received the intervention (Intervention Unit - IU) and one of the Paediatric Units in Teaching Hospital, Batticaloa functioned as control (Control Unit $\mathrm{CU})$. Children who received treatment in the respective paediatric units during the study period comprised the study population. Prescriptions issued to these children were employed to assess the medicines use.

Data on medicines use in children were collected from both units (IU and CU) in three phases - Baseline (Phase 0 ), three months after (Phase 1 ), and one year after the intervention (Phase 2). Phase 0, Phase 1 and Phase 2 data collections were done in April-June 2012, SeptemberNovember 2012 and October-November 2013 respectively. The sample size for each arm for each phase was calculated to detect a minimum change of $15 \%$ in the indicators as a result of the intervention [9].

Intervention: After the completion of Phase 0 data collection, the intervention was offered to one unit. The intervention comprised:

1. Distribution of a personal copy of an independent drug formulary for children [Model WHO formulary for children (WHOMFc)] to all the prescribers and the nurses in the unit.

2. A half-day workshop to all the prescribers and the nurses in the unit. The sessions in the workshop included an outline of RUM in children, the importance of using an independent drug formulary, and a hands-on session on using WHOMFc.

3. Support by clinical pharmacologists. Prescribers and nurses were encouraged to contact the research team (mobile numbers were given) if they encounter any issues related to medicines use in their patients.
Description of outcome: The medicines use was assessed by using 14 indicators (Box A). The WHO prescribing indicators, which were developed, validated and published in 1993 [10] had been employed by many researchers to describe medicines use in health facilities [11-17]. The WHO core indicators are highly standardised, do not need national adaptation, and are recommended to be included in any medicines use study. The indicators are simple and can be measured by information available in patients' Bed Head Tickets (BHTs) and drug charts. We also perused the literature, discussed with the paediatricians of the study units and selected a few more indicators to widen the scope of this study [18].

Box A. Outcome indicators used in assessing the medicines use in children

\begin{tabular}{|c|c|}
\hline Indicator & Reason for selection \\
\hline $\begin{array}{l}\text { 1. Average number } \\
\text { of drugs per prescription }\end{array}$ & WHO - Core (10) \\
\hline $\begin{array}{l}\text { 2. Percentage of } \\
\text { drugs prescribed by } \\
\text { generic name }\end{array}$ & WHO - Core (10) \\
\hline $\begin{array}{l}\text { 3. Percentage of prescriptions } \\
\text { with an antibiotic prescribed }\end{array}$ & WHO - Core (10) \\
\hline $\begin{array}{l}\text { 4. Percentage of prescriptions } \\
\text { with an injection prescribed }\end{array}$ & WHO - Core (10) \\
\hline $\begin{array}{l}\text { 5. Percentage of drugs prescribed } \\
\text { from the National Essential } \\
\text { Medicine List (EML) }\end{array}$ & WHO - Core (10) \\
\hline $\begin{array}{l}\text { 6. Percentage of drugs which } \\
\text { are listed in the WHOMFc }\end{array}$ & WHO - Core (10) \\
\hline $\begin{array}{l}\text { 7. Percentage of patients } \\
\text { treated without regular drugs }\end{array}$ & $\begin{array}{l}\text { WHO - Comple- } \\
\text { mentary (10) }\end{array}$ \\
\hline $\begin{array}{l}\text { 8. Percentage of drugs written } \\
\text { with incomplete dosing } \\
\text { schedule }\end{array}$ & DBI* \\
\hline $\begin{array}{l}\text { 9. Percentage of patients who } \\
\text { received recommended } \\
\text { doses of paracetamol }\end{array}$ & DBI* \\
\hline $\begin{array}{l}\text { 10. Percentage of drugs written } \\
\text { in abbreviation }\end{array}$ & DBI* \\
\hline $\begin{array}{l}\text { 11. Percentage of illegible } \\
\text { prescriptions }\end{array}$ & DBI* \\
\hline $\begin{array}{l}\text { 12. Percentage of drug charts } \\
\text { which had information on } \\
\text { body weight of the child }\end{array}$ & DBI* (18) \\
\hline $\begin{array}{l}\text { 13. Percentage of drugs which had } \\
\text { the reason for prescription } \\
\text { recorded in the BHT }\end{array}$ & DBI* (18) \\
\hline $\begin{array}{l}\text { 14. Percentage of drugs prescribed } \\
\text { according to the recommended } \\
\text { doses }\end{array}$ & DBI* \\
\hline
\end{tabular}

*DBI= Developed by investigators 
A pre-tested, structured data record sheet was used to extract the required data from the drug charts in the BHTs. Additional information (e.g. body weight, reason for prescribing) were obtained from patient notes in the BHT. Prescriptions or drug charts are considered a valuable data source for medicines use studies [19]. Trained data collectors under the supervision of investigators collected data in both units during all three phases. Each day, few randomly selected data record sheets were cross checked to ensure validity of the data collection process. A weakness in prospective data collection to assess medicines use is the bias due to prescribers being aware that their prescriptions are under scrutiny. However, this was minimised in our study as all doctors and nurses were clearly informed about the objectives of the study and importance of valid results. They were also assured that it was not a "fault finding mission", but done with the intention to improve medicines use in children.

All appropriate precautions were taken to ensure accurate entry of data in the database. This database was developed by the investigators using Microsoft Access programme. Results were presented for each indicator for each unit for each phase (phases 1, 2 and 3 are denoted as $\mathrm{C}_{0}, \mathrm{C}_{1}, \mathrm{C}_{2}$, for $\mathrm{CU}$ and $\mathrm{I}_{0}, \mathrm{I}_{1}, \mathrm{I}_{2}$ for IU respectively). Appropriate denominators were used in the calculation. When rationality of doses was analysed, topical preparations, vitamins, probiotics, blood products, off label use (absence of age specific dose) and drugs with missing doses were excluded. Percentage changes were calculated to demonstrate changes in the indicators. Chi-square (categorical data) and t test (numerical data) were used to determine significance of changes for selected indicators (Phase 0 vs Phase 1 and Phase 1 vs Phase 2). $p<0.05$ was considered as statistically significant. Approval was obtained from the Ethics Review Committee, Faculty of Medicine, University of Jaffna (J/ERC/12/26/NDR/0025) and administrative approvals were obtained from the Directors and concerned consultants of the two hospitals.

\section{Results}

The study sample included 1134 drug charts: 735 in

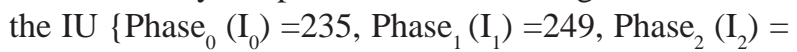
251 \} and 399 in the $\mathrm{CU}$ \{ Phase $_{0}\left(\mathrm{C}_{0}\right)=159$, Phase ${ }_{1}\left(\mathrm{C}_{1}\right)=$ 96 , Phase $\left._{2}\left(C_{2}\right)=144\right\}$. Since each drug chart could have more than one drug, the number of drugs analysed was

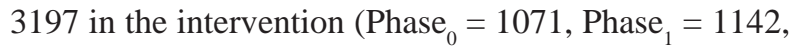
Phase $_{2}=984$ ) and 1539 in the control (Phase $=651$, Phase $_{1}$ $=340$, Phase $_{2}=548$ ) unit. Children aged $1-6$ years comprised about $40-50 \%$ of the total sample in each unit in each phase.

\section{Status of medicines use in Phase 0}

Nine of the 14 indicators, namely, (i) drugs prescribed by generic name, (ii) drugs prescribed from the essential medicines list (iii) drugs listed in the WHOMFc, (iv) children getting the recommended doses of paracetamol, (v) availability of information on body weight (vi) drugs written in abbreviations, (vii) drugs with incomplete dosing schedule, (viii) illegibility and (ix) drugs prescribed according to recommended doses were found to be satisfactory in both units (Table 1).

Percentage of drugs which had the reason for prescribing them recorded in the BHT in the IU (48\%) was unsatisfactory and considerably lower than that of CU (76\%). The following four indicators, namely mean number of drugs per prescription $\left(\mathrm{I}_{0}=4.5, \mathrm{C}_{0}=4.1\right)$, prescriptions with an antibiotic $\left(\mathrm{I}_{0}=48.5 \%, \mathrm{C}_{0}=59 \%\right)$, prescriptions with an injection ( $\mathrm{I}_{0}=25 \%, \mathrm{C}_{0}=28 \%$ ), and patients treated without regular drugs $\left(\mathrm{I}_{0}=6.4, \mathrm{C}_{0}=0\right)$ cannot be commented without knowing the clinical scenario.

\section{Status of medicines use in Phase 1}

Statistical analysis was not performed for two indicators, namely illegibility and availability of information on body weight as they remained ideal and near ideal in both units across the three phases. Changes in the rest of the indicators in the IU (from $\mathrm{I}_{0}$ to $\mathrm{I}_{1}$ ) were compared with that of $\mathrm{CU}$ (from $\mathrm{C}_{0}$ to $\mathrm{C}_{1}$ ) by (1) percentage change, and (2) significance testing (Tables 1 and 2). Average number of drugs prescribed showed a statistically significant reduction in the $\mathrm{CU}\left(\mathrm{C}_{0}=4.09 \pm 1.8, \mathrm{C}_{1}=3.54 \pm 1.9, p<0.05\right)$ as opposed to a slight increase observed in the IU $\left(\mathrm{I}_{0}=\right.$ $4.56 \pm 3, I_{1}=4.59 \pm 3.1$ ).

Overall, in the IU, none of the indicators showed a substantial change after the intervention except percentage of drugs that had the reason for prescription recorded in the BHT, which showed a percentage increase of 73\% ( $\mathrm{I}_{0}$ $\left.=48.1 \%, \mathrm{I}_{1}=83.3 \%, p<0.05\right)$ and statistically significant improvement was also observed in the $\mathrm{CU}\left(\mathrm{C}_{0}=76 \%\right.$, $\left.\mathrm{C}_{1}=87.6 \%, p<0.05\right)$; the magnitude of the increase was much greater in IU (15\% vs. 73\%) (Tables 1 and 2). Another two indicators, namely percentage of children treated without regular drugs and children who received recommended doses of paracetamol, recorded a negligible increase in both setting.

Despite the intervention there was a significant drop $(p<0.05)$ in percentage of drugs prescribed according to recommended doses in IU (67.3\% vs. $61.0 \%)$ while an increase seen in CU (62.3\% vs. 66.8\%). Four indicators showed an unfavorable change in both units, but the magnitude of such change appeared to be less in the IU than that was observed in the CU (Table 2); (i) drugs prescribed by generic name (11.64 vs 23.57), (ii) prescriptions with an injection (5.58 vs 50.88), drugs prescribed from EML (2.25 vs 3.94), and (iv) drugs written in abbreviations (134.78 vs 321.88). Interestingly even after issuing a personal copy of WHOMFc, the percentage of prescribed drugs which are listed in the WHOMCs dropped by $7 \%$ in the IU whereas the drop in the CU (where intervention did not take place) was 3\%. 
Table 1. Indicators in control and intervention units in all three phases

\begin{tabular}{|c|c|c|c|c|c|c|}
\hline \multirow[t]{2}{*}{ Indicators } & \multicolumn{2}{|c|}{ Phase 0} & \multicolumn{2}{|c|}{ Phase 1} & \multicolumn{2}{|c|}{ Phase 2} \\
\hline & $C_{0}$ & $I_{0}$ & $C_{1}$ & $I_{1}$ & $C_{2}$ & $I_{2}$ \\
\hline $\begin{array}{l}\text { Average number of drugs } \\
\text { per prescription }\end{array}$ & $4.09 \pm 1.8$ & $4.56 \pm 3$ & $3.54 \pm 1.9^{\dagger}$ & $4.59 \pm 3.1$ & $3.81 \pm 1.6$ & $3.92 \pm 3^{\circ}$ \\
\hline $\begin{array}{l}\text { Percentage of drugs prescribed } \\
\text { by generic name }\end{array}$ & 81.9 & 71.3 & 62.6 & 63.0 & 70.3 & 55.8 \\
\hline $\begin{array}{l}\text { Percentage of prescriptions with an } \\
\text { antibiotic prescribed }\end{array}$ & 59.1 & 48.5 & 44.8 & 53.8 & 52.1 & 53.4 \\
\hline $\begin{array}{l}\text { Percentage of prescriptions with an } \\
\text { injection prescribed }\end{array}$ & 28.3 & 25.1 & 42.7 & 26.5 & 33.3 & 28.7 \\
\hline $\begin{array}{l}\text { Percentage of drugs prescribed from } \\
\text { the National EML }\end{array}$ & 86.3 & 84.6 & 82.9 & 82.7 & 84.5 & 80.8 \\
\hline $\begin{array}{l}\text { Percentage of drugs which are listed } \\
\text { in the WHOMFc }\end{array}$ & 71.3 & 68.3 & 69.1 & 63.2 & 62.4 & 64.2 \\
\hline $\begin{array}{l}\text { Percentage of patients treated without } \\
\text { regular drugs }\end{array}$ & 0.0 & 6.4 & 1.0 & 7.6 & 0.0 & 12.0 \\
\hline $\begin{array}{l}\text { Percentage of drugs written with } \\
\text { incomplete dosing schedule }\end{array}$ & 2.5 & 8.0 & 2.6 & 8.7 & 3.1 & 10.8 \\
\hline $\begin{array}{l}\text { Percentage of patients received } \\
\text { recommended doses of paracetamol }\end{array}$ & 95.5 & 87.4 & 97.1 & 87.5 & $88.1^{\circ}$ & $94.5^{\circ}$ \\
\hline Percentage of drugs written in abbreviations & 3.2 & 6.9 & 13.5 & 16.2 & 18.4 & 29.6 \\
\hline Percentage of illegible prescription & 0.0 & 0.0 & 0.0 & 0.0 & 0.0 & 0.0 \\
\hline $\begin{array}{l}\text { Percentage of drug charts which had } \\
\text { information on body weight of the child }\end{array}$ & 100.0 & 99.1 & 95.8 & 97.2 & 98.6 & 98.4 \\
\hline $\begin{array}{l}\text { Percentage of drugs which had the reason } \\
\text { for prescription recorded in the BHT }\end{array}$ & 76.0 & 48.1 & $87.6^{\dagger}$ & $83.3^{\dagger}$ & 87.4 & $92.0^{\circ}$ \\
\hline $\begin{array}{l}\text { Percentage of drugs prescribed according } \\
\text { to the recommended doses }\end{array}$ & 62.3 & 67.3 & 66.8 & $61.1^{\dagger}$ & 61.0 & $68.3^{\circ}$ \\
\hline
\end{tabular}

${ }^{\dagger}$ statistically significant difference seen between Phase 0 and Phase 1

○ statistically significant difference seen between Phase 1 and Phase 2

There was an increase in percentage of drugs written with incomplete dosing schedule in both setting, but the increase was more than double in the IU when compared to CU ( $8.75 \%$ vs $4 \%$ ). Table 1 and 2 clearly show that the intervention failed to produce a favourable influence on any of the six WHO core indicators.

\section{Status of medicines use in Phase 2}

Results are shown in Table 1. The objective of Phase 2 was to determine the sustainability of the favourable changes observed in the IU in Phase 1 . The three indicators, namely, percentage of drugs that had the reason for prescription recorded in the BHT, percentage of children treated without regular drugs and percentage of patients received recommended doses of paracetamol, which showed favourable changes in three months in the IU, sustained the improvement in Phase 2 as well. But, the improvement was statistically significant $(p<0.05)$ only for one indicator (drugs which had the reason for prescription recorded in $\mathrm{BHT})$.

\section{Discussion}

Though the intervention offered in this study has not produced major changes in medicines use in children, the results provide some key messages to plan future studies and to identify suitable interventions to improve medicines use in children in Sri Lanka. 
Table 2. Percentage change* in indicators in control and intervention setting in phase 1 and phase 2

\begin{tabular}{|c|c|c|c|c|}
\hline \multirow[t]{2}{*}{ Indicators } & \multicolumn{2}{|c|}{ Phase 1} & \multicolumn{2}{|c|}{ Phase 2} \\
\hline & $C U$ & $I U$ & $C U$ & $I U$ \\
\hline Average number of drugs per prescription & -13.47 & +.066 & -6.85 & -14.04 \\
\hline Percentage of drugs prescribed by generic name & -23.57 & -11.64 & -14.16 & -21.74 \\
\hline Percentage of prescriptions with an antibiotic prescribed & -24.2 & +10.93 & -11.83 & +10.1 \\
\hline Percentage of prescriptions with an injection prescribed & +50.88 & +5.58 & +17.67 & +14.34 \\
\hline Percentage of drugs prescribed from the National EML & -3.94 & -2.25 & -2.09 & -4.49 \\
\hline Percentage of patients treated without regular drugs & NA & +18.75 & NA & +87.5 \\
\hline $\begin{array}{l}\text { Percentage of drugs which are listed in the WHO } \\
\text { Model Formulary for children }\end{array}$ & -3.09 & -7.47 & -12.48 & -6.15 \\
\hline Percentage of drugs written with incomplete dosing schedule & +4 & +8.75 & +24 & +35 \\
\hline Percentage of patients received recommended doses of paracetamol & +1.68 & +0.1 & -7.75 & +8.12 \\
\hline Percentage of drugs written in abbreviations & +321.88 & +134.78 & +475 & +328.9 \\
\hline Percentage of illegible prescription & NA & NA & NA & NA \\
\hline $\begin{array}{l}\text { Percentage of drug charts which had information on body } \\
\text { weight of the child }\end{array}$ & -4.2 & -1.92 & -1.4 & -0.71 \\
\hline $\begin{array}{l}\text { Percentage of drugs which had the reason for prescription } \\
\text { recorded in the BHT }\end{array}$ & +15.26 & +73.18 & +15 & +91.27 \\
\hline Percentage of drugs prescribed according to the recommended doses & +7.22 & -9.21 & -2.09 & +1.49 \\
\hline
\end{tabular}

* - Percentage change $=($ Phase 1 or Phase 2 - Phase 0$) /$ Phase $0 \times 100$ NA - Not applicable as one or more value/s is/are 0 .

The intervention did not produce a significant effect on medicines use in children in the IU which is a University unit in a Teaching Hospital. Hence, the chances are remote for it to be successful at other levels of hospitals. We planned this intervention partly to introduce the habit of using a formulary. Absence of an up to date National Formulary and lack of free availability of British National Formulary led us to use the WHOMFc which gives independent information for medicines listed in the WHO model essential medicines list for children. Lack of training and limited access to independent paediatric specific information had been recognised as challenges to practice RUM in children in developing countries [20]. Yet, when we tried to address these two deficiencies in a single unit in a Teaching Hospital (which has a staff strength of about four doctors and nine nurses) by providing personal copies of WHOMFc following a training workshop and opportunity to contact a clinical pharmacologist in the research team, the outcome was not impressive. The possible reasons could be: (1) habit of referring a formulary and seeking independent information are not part of individual patient care, (2) low acceptability of a new formulary (3) a half-day workshop was inadequate to change the prescribing practice and to introduce the culture of using formulary in individual patient care (4) insufficient information in the formulary (5) unsuitability of indicators to compare the medicines use in children before and after an intervention, and (6) intervention to improve medicines use should be stronger, continuous, sustainable and multi-faceted than the intervention offered in this study.

While four of the twelve core interventions proposed by the WHO targeted education, training and information, the other eight were directed at policy framework, supportive regulations and adequate resources [7]. Our study has documented that the intervention targeting first four will not be effective in the absence of a policy, 
regulations and resources. We believe that any such intervention should be long term, linked to regulations, attractive to users and started at the very early stage of medical training. In fact, the WHO proposes that problembased pharmacotherapy should be introduced in undergraduate curricula, continuing in-service medical education to be made as a licensure requirement, and medicines use to be supervised and audited [7]. We call on the relevant authorities to bring in and strictly enforce such interventions to promote RUM.

In a study like this, the tool plays a major role. We used 14 indicators as the tool to assess the medicines use in children. The process of selecting these indicators had been clearly described in the methods section. From the results we have learnt that the majority of these indicators were general medicines use indicators and lacked the sensitivity to identify child specific issues. Administering medicines to children poses special challenges. However, the indicators lacked the ability to assess the administration practice. This problem was evident in the literature where paediatric studies using the WHO prescribing indicators though report the common issues in medicines use, failed to document the special challenges in children $[11,21,22,23]$.

The general medicines use indicators will not identify the challenges in paediatric pharmacotherapy. Separate set of indicators are required to assess these special challenges in children. For example, we developed seven new indicators for the current study (Table 1). At least three had been promising (drugs prescribed according to the recommended doses, drugs written with incomplete dosing schedule and children getting recommended doses of paracetamol). Drugs written with incomplete dosing schedule, has increased from $8 \%$ to $10.8 \%$ in the IU despite the intervention. This indicator has picked up an issue which demands further analysis of data and remedial actions based on the results. The other new indicator, children getting the recommended doses of paracetamol, was good in both units in and showed a statistically significant increase in $\mathrm{I}_{2}$ as opposed to a significant drop in $\mathrm{C}_{2}$. The indicator has delivered a strong message regarding accuracy of paracetamol dose calculation which can be used to improve rational use of paracetamol in the respective units.

Few individual general medicines use indicators merit discussion. Percentage of drugs prescribed by generic name was unsatisfactory in the IU, 71\% in $\mathrm{I}_{0}$ and $55 \%$ in $\mathrm{I}_{2}$. It is unacceptable for a Teaching Hospital and will set a bad example for undergraduates. Similar studies from other countries have reported varying results (19\% to 82\%) [11, $21,22]$. Percentage of drugs written in abbreviation was also unsatisfactory in both units with gross inter-phase difference in IU indicating complete failure of the intervention (6.9\% in $\mathrm{I}_{0}, 29.6 \%$ in $\mathrm{I}_{2}$ ). This could be partly due to prescription writing style of different house officers who were rotated every 6 months. However, a study from UK [23] also reported that $24 \%$ of drugs prescribed for inpatients were written in abbreviation. Development and strict enforcement of either hospital or ward based policy on uniform prescription writing style could improve these indicators.

Percentage of drugs prescribed from the National EML appears to be commendable (above $80 \%$ ) in both units in all three phases. This could be partly due to the fact that supply to hospital pharmacies is mostly confined to essential medicines.

When calculating percentage of drugs prescribed according to recommend doses, we found that about 5\% of drugs prescribed in CU (5-6.3\%) and IU (4.4-4.8\%) were not recommended for children or for the particular age group (off label use). In addition, doses were missing for $0.8-1.4 \%$ of drugs in CU and 1.2-2.4\% of drugs in IU.

To best of our knowledge this is the first study that has reported the status of medicines use in children from two Teaching Hospitals in Sri Lanka. The study has used the standard WHO core indicators, thus comparison with studies from other countries is feasible. In addition, few additional indicators were also assessed for their ability to identify status of medicines use in children. Moreover, the study has provided evidence that multi-faceted interventions are required to promote RUM in children in Sri Lanka. The study was not without limitations: We could not get the calculated sample size in the CU. Secondly, the indicators developed by the investigators (DBI) are not formally validated. However, with the experience from this study, we have already started the formal process of developing and validating paediatric specific indicators which can be supplementary to the WHO core indicators.

In conclusion, medicines use in children as measured by the WHO core indicators seem to be satisfactory and on par with previous published studies. However, to quantify the special challenges in paediatric pharmacotherapy, paediatric specific indicators are required. Multifocal interventional programmes are crucial to promote RUM.

\section{Acknowledgments}

We thank Mr. S. Thayaparan for the technical support, data collectors Sunnentha Sriskantharajah, Ealily Nagarasa and Gayathri Ganeshamoorthy, Prof. Nalika Gunawardena for providing expert opinion on statistics and doctors and nurses of both paediatric units for their support.

\section{Conflicts of interest}

There are no conflicts of interest. 


\section{References}

1. World Health Organization. The rational use of drugs. Report of the Conference of Experts. Geneva: WHO; 1985.apps.who.int/medicinedocs/documents/s17054e/ s17054e.pdf (accessed on Mar 04, 2016)

2. World Council of Churches. Promoting rational use of medicines. Contact. 2006 Oct-Nov;183. http://apps.who.int/ medicinedocs/documents/s19836en/s19836en.pdf. (accessed on Mar 04, 2016)

3. World Health Organization. Ensuring the Right Medicine in the Right Formulation for Every Child. Geneva World: WHO; 2006.

4. Barker C, Nunn AJ, Turner S. Paediatrics, in: Walker R, Edwards C, eds. Clinical Pharmacy and Therapeutics. 3rd ed. Churchill Livingstone 2004: 111-26.

5. Koren G. Special Aspects of Perinatal and Paediatric Pharmacology. In: Katzung BG, Trevor AJ, eds. Basic and Clinical Pharmacology. 11th ed. McGraw-Hill, 2007: 1025-36.

6. Nahata MC, Taketomo C. Paediatrics. In: Di Piro JT, Talbert RL, Yee GC, et al. eds. Pharmacotherapy: A Pathophysiologic Approach. 7th ed. McGraw-Hill, 2010: 47-56.

7. WHO Policy Perspectives on Medicines Promoting Rational Use of Medicines: Core Components, September 2012, Geneva: WHO.

http://www.who.int/medicines/publications/ policyperspectives/ppm05en.pdf (assessed on Mar 04, 2016).

8. Cook TD, Campbell DT. Quasi-experimentation: Design and Analysis Issues for Field Settings. Chicago: Rand McNally, 1979.

9. Hulley SB, Cummings SR, Browner WS, et al. Designing Clinical Research, An epidemiologic approach. 2nd ed. Lippincott Williams \& Wilkins, 2001.

10. How to investigate medicines use in health facilities; selected medicines use indicators. Action Programme on Essential Drugs. World Health Organisation, 1993; 9-16.

www.who.int/medicinedocs/pdf/s2237e/s2237e.pd. (accessed on Mar 04, 2016).

11. Satish Kumar BP, Ghimire P, Praveen Kumar, Anjaiah B. A study on medicines use pattern using who prescribing indicators in in-patients of medicine department in a rural tertiary care teaching hospital. Indo Am J Pharmaceuti Res 2015; 15: 2041-46.

12. Thiruthopu NS, Mateti UV, Bairi R, et al. Drug utilization pattern in South Indian pediatric population: A prospective study. Perspect Cln Res 2014; 5: 178-83.

13. Ferreira MBC, Heineck I, Flores LM et al. Rational use of medicines: prescribing indicators at different levels of health care. Braz J Pharm Sci 2013; 49: 329-40.

14. El Mahalli AA. WHO/INRUD drug prescribing indicators at primary health care centres in Eastern province, Saudi Arabia. East Mediterr Health J 2012; 18: 1091-96.

15. Afsan M, Haque MME, Alam MM, Noor N. Audit of Prescribing Practices to Evaluate Rational Use of Medicines in the OPD of Orthopaedics in a Private Medical College Hospital. J Shaheed Suhrawardy Med Coll 2012; 4: 39-42.

16. Dahal P, Bhattarai B, Adhikari D, et al. Drug use pattern in primary health care facilities of Kaski district, Western Nepal. Sunsari Tech Coll J 2012; 1: 1-8.

17. Karande S, Sankhe M, Kulkarni M. Patterns of Prescription and Drug Dispensing. Indian J Pediat 2005; 72: 117-21.

18. Indicators of Quality Prescribing in Australian General Practice. National Prescribing Service Limited, 2006. http://www.nps.org.au/_data/assets/pdf_file/0019/37351/ indicators_full.pdf. (accessed on Mar 04,2016).

19. Sources of data on drug utilization, Introduction to Drug Utilization Research. WHO, 2003: 21-22.apps.who.int/ medicinedocs/pdf/s4876e/s4876e.pdf. (accessed on Mar 04, 2016).

20. Hoppu K, Sri Ranganathan S, Dodoo AN. Realities of paediatric pharmacotherapy in the developing world. Arch Dis Child 2011; 96: 764-8.

21. Vishwanath M, Narayana Reddy S, Devadas S. Assessment of drug utilization in hospitalized children at a tertiary care teaching hospital. J Chem Pharm Res 2014; 6: 592-8.

22. Agalu I A, Mekonnen H. Drug prescribing practice in a pediatrics ward in Ethiopian. Int Res $J$ Pharm Pharmacol 2012; 2: 132-38.

23. Ghaleb AM, Barber N, Franklin BD, Kei Wong IC. The incidence and nature of prescribing and medication errors in paediatric inpatients. Arch Dis Child 2010; 95: 113-8. 